\title{
Railway Noise Pollution Prevention in Terms of Regulations: Case Study of Istanbul
}

\author{
Göksel Demir, Ayşe Kablan, Yaşar Avşar, Ümmügülsüm Alyüz, Hatice Eser Ökten, and Şenay Yalçın
}

\begin{abstract}
Rail transport, being one of the major sources of ambient noise, causes an uncomfortable environment for the people living around railways. In Turkey, "Regulation on Assessment and Management of Environmental Noise" was published in 2010 in order to prevent noise-induced annoyance. In this study, preparation stages of generating a noise action plan was investigated by using case studies from Istanbul, which has not been applied to railway lines in Turkey yet. To this end, results from a detailed questionnaire, which examines effects of the noise on the people living around railways, were assessed, components of the study to reduce noise were described, a method of analysis was presented to design a noise barrier with cost effective considerations. Despite noise barrier is an expensive measure, it was one of the measures given on the local regulation, and therefore it was applied in this study. This study is intended to provide a roadmap for decision-makers and practitioners.
\end{abstract}

Index Terms - Noise, pollution, railway.

\section{INTRODUCTION}

Railway noise is categorized as a discrete noise type that creates spikes in time-dependent noise diagrams. The continuity of this type of noise is low, hence it causes less sleep disturbance; but makes communication rather difficult due to its high magnitude. Dissemination of noise at highways may vary depending on rotations per minute of the engine even for similar types of vehicles being operated at the same speeds. Thus, it is almost identical for similar type of railway vehicles, which are operated at similar speeds. Road traffic progresses irregularly and it cannot be predicted in advance; however railway traffic moves in accordance with a pre-determined plan. On average, roadway noise causes 5 $\mathrm{dBA}$ less disturbance than airline noise and $5 \mathrm{dBA}$ more disturbance than railway noise [1].

In Europe, passenger traffic and freight traffic are planned to increase by $200 \%$ and $300 \%$ respectively in the next 20 years. Every day $10 \%$ of the EU population is exposed to rail noise above $55 \mathrm{~L}_{\mathrm{Aeq}} \mathrm{dB}$ [2]. According to a study conducted in the USA, when railway noise exceeds $70 \mathrm{dBA}\left(\mathrm{L}_{\mathrm{dn}}\right), 30 \%$ of the population is disturbed, and the percentage increases to

Manuscript received September 25, 2014; revised May 15, 2015.

Göksel Demir, Ümmügülsüm Alyüz, Hatice Eser Ökten, and Şenay Yalçın are with the Bahcesehir University Environmental Engineering Department, Besiktas Istanbul, Turkey (e-mail: goksel.demir@eng.bahcesehir.edu.tr, ummugulsum.alyuz@bahcesehir.edu.tr,_eser.okten@bahcesehir.edu.tr, senay.yalcin@bahcesehir.edu.tr).

Ayşe Kablan is with Turkey Republic State Railway Department, Turkey (e-mail: kablanayse@gmail.com).

Yaşar Avşar is with Yildiz Technical University Environmental Engineering Department, Turkey (e-mail: yavsar@gmail.com.tr).
$45 \%$, when the railway noise exceeds $80 \mathrm{dBA}$ [3].

According to Nijland et al. [4], noises (mainly traffic noises) in residential locations influence the level of satisfaction with the living environment, and noise-sensitive people more often consider moving. Ryu and Jeon [5] conducted a survey and a laboratory experiment to investigate the influence of noise sensitivity on the annoyance caused by indoor residential noises and outdoor traffic noise. They found that, annoyance was $35 \%$ correlated with noise sensitivity in the surveys and $14 \%$ in the laboratory experiments, in which noise exposure was controlled at $50 \mathrm{dBA}$, and results showed that noise sensitivity significantly influenced the annoyance level caused by both indoor and outdoor noise.

Turkish Regulation on Assessment and Management of Environmental Noise [6], which was enforced in 2010 as a part of the alignment processes with Environmental Noise Directive [7] of European Union (EU) legislation, stated that necessary precautions should be taken to preserve physical and mental health of people in the incident of exposure to environmental noise. In order to achieve this goal, exposure rates for environmental noise should be determined by preparing noise maps, acoustic reports, and environmental noise exposure level evaluation reports for the main railway lines. Then, the public should be informed about environmental noise and its effects by considering reported data. Preparation of action plans for prevention and reduction of noise is required for locations where exposure to environmental noise levels may cause harmful effects on human health. Deadlines for preparing noise maps and action plans are specified in the Turkish Regulation [6] which is lately in 2014. Noise maps and action plans are prepared for settlements and areas outside the residential areas by municipalities and the Transport, Maritime Affairs and Communications Ministry. Noise maps and action plans are reviewed every five years and they are revised if deemed necessary.

In Turkey, by the year 2012 there were three lines of about $96.9 \mathrm{~km}$ with more than 60,000 trains passing annually (Haydarpaşa-Gebze, Alsancak-Cumaovası, BasmaneMenemen) and three lines of about $120.5 \mathrm{~km}$ with 30,000-60,000 trains passing annually (Sirkeci-Halkal1, Menemen-Aliağa, Adana-Mersin), which corresponds to approximately 82-165 trains per day. The rest of the lines had less than 30,000 trains passing in a year. According to Ahrlin (1988) [8], approximately $13 \%$ of the people are very annoyed, $45 \%$ complained from speech interference, 35\% complained from rest/sleep interference and $25 \%$ complained from awakening, which are living in the areas exposed to a maximum train noise level of $80 \pm 3 \mathrm{~dB}(\mathrm{~A})$ where $80-100$ trains passing per day. For none of the lines in Turkey, noise maps were prepared by the Ministry, the noise maps are 
expected to be completed in 2013 [9]. As part of the noise-mapping required by the European Commission's Environmental Noise Directive, a number of randomly chosen persons exposed in the vicinity of railway lines with relatively heavy traffic will be surveyed and published by infrastructure managers starting in 2007 [7].

In this study, preparation stages of a noise action plan was investigated by using case studies from Istanbul by considering the local Regulation, which has not been applied to railway lines in Turkey yet. To this end, results from a detailed questionnaire which examines effects of noise on people living around railways were assessed; components and stages of the study to reduce noise were described. There already exist such studies in the literature for different railway locations. For instance, Elmenhorst et al. [10] evaluated nocturnal noise annoyance in Cologne/Bonn (Germany) by conducting a survey with 33 participants living along a railway. Saadu et al. [11] conducted a noise survey for eight Nigerian cities to investigate noise annoyances from construction activities. As a conclusion a method of analysis was presented to design a noise barrier with effective considerations.

\section{MATERIALS AND METHOD}

The methodology followed in this study is presented in Fig. 1 for railways that meet the criteria specified in Turkish Regulation [6] and need to start the planning process.

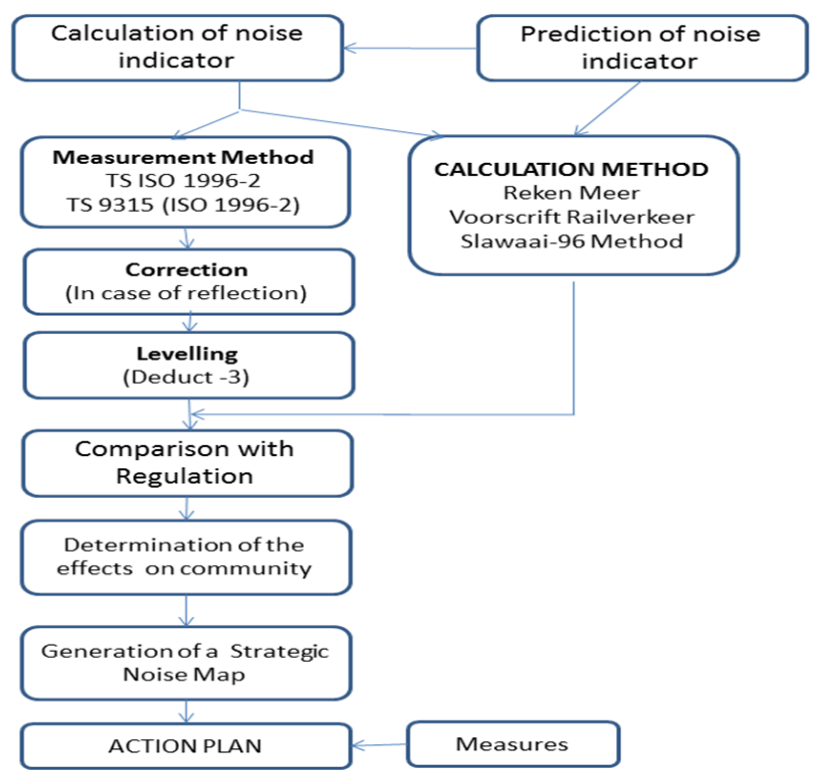

Fig. 1. Methodology summary according to the regulation on assessment and management of environmental noise [3].

Environmental noise indicator calculation is generally conducted as the first step in noise mapping however it has to be omitted due to lack of data, instead impact on the community is determined. Participants are surveyed in various age groups and professions in various districts of Istanbul by asking some questions about their annoyances from noise. Fields et al. (2001) [12] recommended a methodology to use in noise surveys and includes a reaction modifier study results for 60 Turkish-language subjects at one site. In this questionnaire format, there is a scale which groups modifier candidates for 4-point scale, which was applied in this study as it is given in Table I as a sample questionnaire that was used in this study.

TABLE I: SAMPLE QUESTIONNAIRE

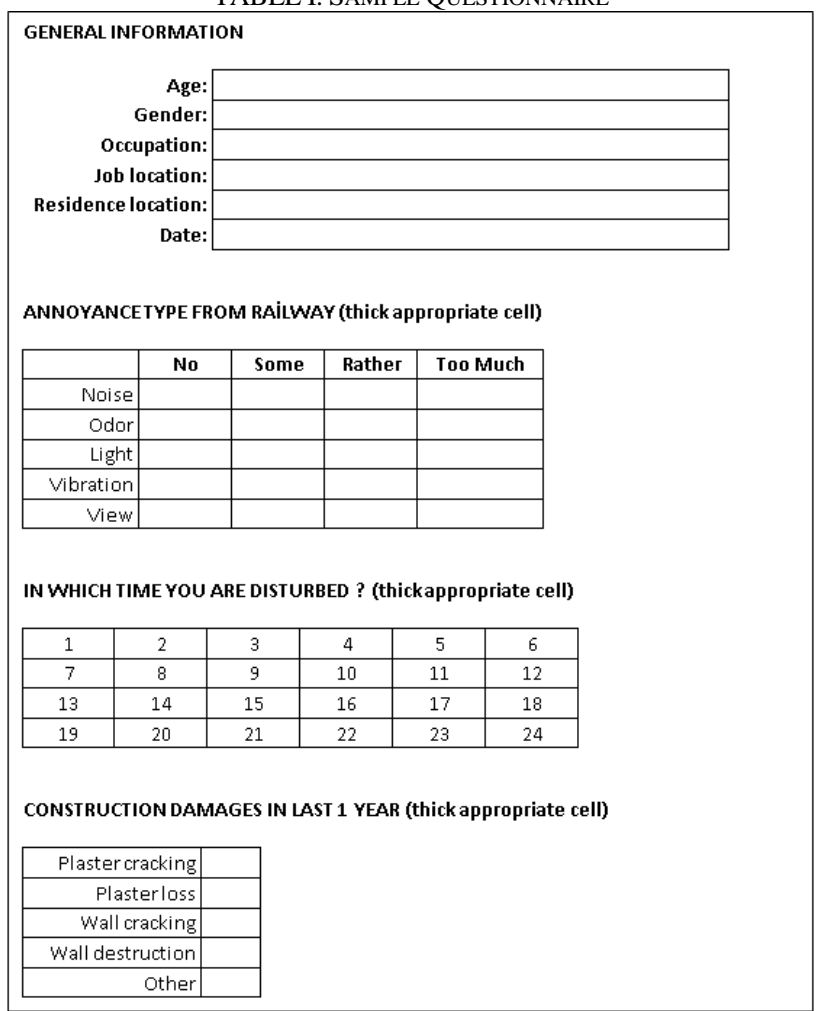

After determining annoyance types at the first stage, an application case is developed in order to support preparation of the strategic noise map. In order to supply a sample for decision makers, a barrier was designed by using Sound Plan V.7.0 Noise Modeling Software for a sample location where impact of noise on the community was high. The last step was preparation of action plans. Some recommendations were given at the last part of the study by considering local regulations [6] which were also compatible with EU regulations [7].

\section{CONDUCTING A SURVEY FOR DETERMINATION OF IMPACT OF NOISE ON COMMUNITY}

In this study, a survey comprised of six questions is conducted with participation of 60 people ( 21 women and 39 men) living at close proximity to railways [13]. The main purpose of the survey is to identify exposure-effect relationships and to determine the harmful effects on the community as stated in the Regulation [3]. In this survey, annoyance factors of noise, vibration, odor, light, and view are included. Participants are asked about their annoyance level and frequency regarding these factors. Also, types of damages to their houses due to these factors and their expectations from authorities are asked. Acquired data are then evaluated at the action plan preparation phase.

Age and employment status demographics are presented in Fig. 2. According to these demographics, the biggest and smallest shares in employment status distribution belong to the housewife-unemployed-student group and senior management, respectively. The age distribution is dominated by the $40-60$ age range. 

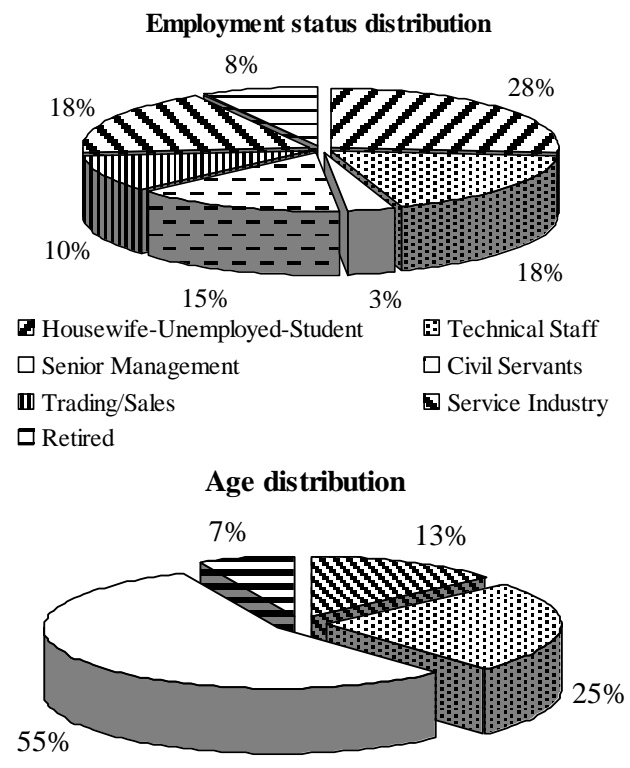

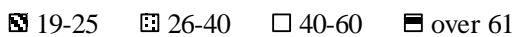

Fig. 2. Employment status distribution and age distribution of 60 participants.

According to replies of other questions, participants live at 9 different districts which are at close proximity to railways. On the other hand, demographics related questions reveal that 24 participants out of 60 do not work in their home districts. $22 \%$ of the respondents state that they are disturbed by noise, followed by vibration $(9 \%)$, odor $(5 \%)$, and view (3\%). The question on annoyance hours is replied by 44 people. Accordingly, $71 \%$ of participants state that they are affected by noise caused by railway traffic during rush hours ( 6 am to $12 \mathrm{pm}$ and $6 \mathrm{pm}$ to $12 \mathrm{am}$ ).

Annoyance level data in regard to all five of the annoyance factors are as follows; $35 \%$ of participants state that they are not affected by any of the five factors. Over $29 \%$ of this group of participants spends most of their time at home. The descending order of annoyance for the factors is given as noise, vibration, view, odor, and light. Noise is found to be the foremost disturbing factor by $36.7 \%$ of participants, followed by vibration $(23 \%)$, odor and view (18\% each), and light (8.6\%). Also $6.7 \%$ and $13.3 \%$ of participants claim to develop a nervous disorder and a physical disorder due to the disturbing factors, respectively. $44 \%$ of men and $20 \%$ of women state that they are not affected by any of the factors.

Observations on vibration induced damage are asked to participants and the percentage of each type of damage observed by participants are as follows; it is found out that railway vibrations do not cause damage to walls, however it may cause cracks on the grout. While $5 \%$ of participants do not answer the question on damage, $13.3 \%$ of respondents declare to observe the grout cracking due to noise.

\section{Generation OF STRATEgic Noise MaP}

In order to reduce noise, strategic noise maps should be prepared in order to develop action plans. At this stage, factors such as noise propagation type, topography of land, status of the railway on land, and train types are considered. For this purpose, initially land is modeled, and then noise maps were generated. As a result, noise action plans are prepared by determining noise-concentrated regions on strategic noise maps, and measures are identified. To this end, an example including all these steps is explained in this study. Technical characteristics of the modeled railway noise source, which are composed of different couch types such as Pullman coach, compartment coach, restaurant coach, couchette coach, saloon and conference couches, have $1435 \mathrm{~mm}$ track gauge, $19000 \mathrm{~mm}$ center pin distance, 42-47 ton vehicle weight (empty- full) [14]. A train is consisted of 12-20 couches and approximately 90 train passes per day from the modeled railway, which is hitting 32,000 train passing per year. First of all, land is modeled in order to detect location of noise sources, and then strategic noise maps are generated by using Sound PLAN V.7.0. Considering current traffic and railway parameters, which actually determine noise level, a noise map is prepared for the close proximity locations. At this stage, current and planned noise impact zones are determined by considering topography and characteristics relevant to settlement. While generating noise maps, buildings that are affected by noise and the number of buildings and floors that are exposed to noise levels higher than exposure limit values specified in the regulations [3] are identified. Next stage is the generation of an action plan, and determining the measures.

\section{Generation of An ACtion Plan}

Noise prevention projects according to action plans are generally expensive, which cause negative impacts on the development of railways. Therefore an optimization study should be done in order to receive cost efficiency.

Current status, which is elucidated through noise maps, is assessed in terms of source, receiver, and transmission path. Possible mitigation measures are then discussed at the design phase of the action plan. Effectiveness of proposed measures is determined by a simulation program. For instance, when a noise barrier is decided to be used as a measure against noise, the most effective barrier system in terms of cost benefit is determined by entering acoustic properties of barrier system into simulation program. Through optimization, maximum efficiency is combined with minimum number of noise barriers. Thus optimized barrier area results the best noise efficiency with the possibilities at hand. Furthermore, establishing barriers is not the only way to reduce noise. For instance, it is well-known that increasing the track decay rate by dedicated "rail dampers" attached to the rail web can considerably reduce rolling noise emission [15]. Number of precautions may be increased.

With 2 meters high, 100 meters long barrier system, the number of people that may be exposed to noise below the limit values are determined (Fig. 3). This process is repeated for 4 meters high, 100 meters long barrier system and the efficiency of the barrier system is evaluated in terms of cost and benefit. Finally, optimization results retrieved from the simulation program are presented in Fig. 3. The most efficient combination is determined by analyzing geographical and acoustic properties for various heights with optimization. For instance, if there is no need for a $4 \mathrm{~m}$ high barrier, then $2 \mathrm{~m}$ high barrier is used, or vice versa. Then cost-benefit data are summarized in a table for $2 \mathrm{~m}$ high, $4 \mathrm{~m}$ high, and 
height-optimized noise barriers. Finally noise levels decreased between 2 to $12 \mathrm{dBA}$. According to predictions of Avsar and Gumus [16], a $4 \mathrm{~m}$ high noise barrier can decrease A-weighted noise levels by 10 to $15 \mathrm{dBA}$. Also, optimization of the proposed barrier system, barrier system features, and improvements are included in the action plan.

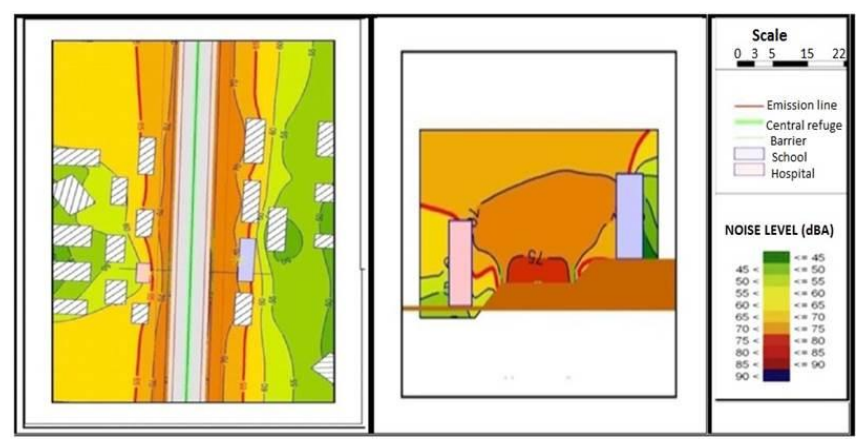

Fig. 3. Optimized design for $2 \mathrm{~m}$ high barrier.

\section{DETERMINATION OF MEASURES-BARRIER DESIGN EXAMPLE}

Noise mitigation projects resulting from action plans are usually very expensive. In those cases, where these costs must be carried by the railways, they may threaten their economic viability in the current harsh competitive transport market, thus hinder their sustainable transport policies. It is therefore necessary to develop strategies which optimally balance noise reduction and cost of measures with regard to European and national legislation [17]. One of the most important methods applied for reduction of noise is source control; improving quality of rail surface, noise level control applications in railway vehicles (usage of Euro 5, Laermschutz (L)), continuous auditing for speed may be applied for reduction of noise induced and time dependent deformation on roads. Furthermore, new railways that are planned for metropolitan areas may be constructed at the outskirts, and restrictions may be applied for high noise generating trains during certain hours. Enveloping railways with tunnels, creating wooded areas around railways may be also viable options if cost-benefit analysis supports.

Implementation of noise barriers may be one of the best solutions for both current and future railways as it is implemented in this study. After applying the mentioned steps above, the effective barrier design is conducted using cost-benefit evaluations to reduce costs effectively. In the current Turkish legislation limit value is $70 \mathrm{dBa}$ Ldn for noise barriers. In this study, noise barrier was applied to a railway which requires noise mitigation. To do this, first of all, noise barrier type is selected by using properties of buildings that are exposed to noise above limit values. Topography, cost, acceptable absorption coefficient, reduction values (sound transmission loss, $\mathrm{dBA}$ ) are considered in the selection of a noise barrier. If buildings are located at both sides of a railway, high absorption materials are selected, otherwise absorption factor is not taken into account. Afterwards, noise maps are prepared with the noise barrier and the number of affected buildings is redetermined. In this study, final heights of noise barriers and geometric shapes are determined by using optimization methods for noise barrier. Then, all data are evaluated for areas that are exposed to noise and an example of barrier optimization is carried out with the help of Sound PLAN V.7.0 software (a sample was supplied in Fig. 3) which is used for noise mapping and action plan preparation in accordance to the EU environmental noise regulations.

The main action plan will be considered after getting railway noise maps either measuring or modeling of it. Also the detailed action plan is given in Regulation4-Appendix V which is also parallel to the European strategies and priorities for railway noise abatement [16]. According to this regulation, an effective action plan can include following measures; traffic planning, land use planning, technical measures at noise sources, selection of less noise generating sources, reduction of sound transmission, (e.g. noise barriers), regulatory or economic measures and incentives. A combination of those measures can be applied to an action plan.

\section{CONCLUSION}

Although noise from rail transport seems to be less disturbing among other transport noises, the main objective should be having least annoyance. In order to achieve least annoyance, competent authorities, whom individuals may contact due to noise annoyance, should be determined by officially. The administrative structure should be established as soon as possible and required measures should be taken in order to evaluate the community's complaints. Periodic measurements on densely populated centers should be conducted by independent laboratories, accordingly the noise sources should be identified and appropriate sanctions should be applied.

Prevention of noise from transport at source is the most economical and effective solution to reduce noise. For instance, long welded rails significantly reduce the impact of noise when used on railways. Constructing appropriate infrastructure to drain water helps preserving the impact of noise, which is absorbing ballast layer and eventually reduces noise at source. Additionally, alternative routes may be created in coordination with municipalities. Noise barriers such as concrete walls, green areas, and land cover reconstruction should be implemented, where limit values are exceeded despite the prevention at source and where route optimization is not possible. Noise reduction can be achieved by integrating all related authorities assigning specified duties and responsibilities stated in the regulation.

\section{REFERENCES}

[1] H. M. E. Miedema and H. Vos, "Exposure-response relationships for transportation noise," Journal of the Acoustical Society of America, vol. 104, issue 6, pp. 3432-3445, 1998 .

[2] J. Lambert, P. Champelovier, and I. Vernet, Railway Annoyance in Europe: An Overview, Euro-Noise 98, Munchen, 1998.

[3] Department of Planning and Infrastructure - The Perth Urban Rail Development Office, "Perth Urban Rail Development Project Supplementary Master Plan," Perth, Western Australia, 2002.

[4] H. A. Nijland, S. Hartemink, I. Kamp, and B. Wee, "The influence of sensitivity for road traffic noise on residential location: Does it trigger a process of spatial selection?" J. Acoust Soc Am, vol. 122, pp. 1595-601, 2007

[5] J. K. Ryu and J. Y. Jeon, "Influence of noise sensitivity on annoyance of indoor and outdoor noises in residential buildings," Applied Acoustics, vol. 72, pp. 336-340, 2011. 
[6] TMoEF, Turkish Ministry of Environment and Forestry, "Regulation on assessment and management of environmental noise," Official Gazette, no. 27601, 2010.

[7] European Commission, Environmental noise directive 2002/49/EG, 2002.

[8] U. Ahrlin, "Activity disturbances caused by different environmental noises," Journal of Sound and Vibration, vol. 127, no. 3, pp. 599-603, 1988.

[9] Turkey Ministry of Maritime Transport and Communication, "Request for information," no. 71480, 2012.

[10] E. Elmenhorst, S. Pennig, V. Rolny, J. Quehl, U. Mueller, H. Maaß, and M. Basner, "Examining nocturnal railway noise and aircraft noise in the field: Sleep, psychomotor performance, and annoyance," Science of the Total Environment, vol. 424, pp. 48-56, 2012.

[11] A. A. Saadu, R. O. Onyeonwu, E. O. Ayorinde, and F. O. Ogisi, "Community attitudinal noise survey and analysis of eight Nigerian cities," Applied Acoustics, vol. 49, no. 1, pp. 49-69, 1996.

[12] J. M. Fields, R. G. D. Jong, T. Gjestland, I. H. Flindell, R. F. S. Job, S. Kurra, P. Lercher, M. Vallet, T. Yano, R. Guski, U. Felscher-Suhr, and R. Schümer, "Standardized general-purpose noise reaction questions for community noise surveys: Research and a recommendation," $J$ Sound Vibr., vol. 242, pp. 641-679, 2001.

[13] A. Kablan, "Noise pollution and disposal methods in railways Evaluation of the relevant legislation," Master dissertation, Bahçeşehir University, Institute of Science, Urban Systems, and Transportation Management Program, 2012.

[14] Tuvasas, "Technical characteristics brochure," Turkish Coach Industry Incorporation.

[15] B. Schulte-Werning, B. Asmussen, W. Behr, K. G. Degen, and R. Garburg, "Advancements in noise and vibration abatement to support the noise reduction strategy of Deutsche Bahn," in Proc. the 10th International Workshop on Railway Noise, Nagahama, Japan, 2010.

[16] Y. Avsar and B. D. Gumus, "The application of noise maps for traffic noise reduction," Noise Control Engineering Journal, vol. 59, issue 6, pp. 715-723, 2011.

[17] J. Oertli, "Developing noise control strategies for entire railway networks," Journal of Sound and Vibration, vol. 293, pp. 1086-1090, 2006.

[18] Working Group Railway Noise of the European Commission, "Position paper on the European strategies and priorities for railway noise abatement," 2003.

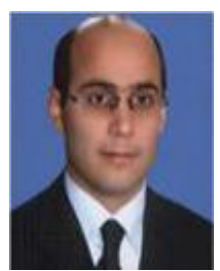

Goksel Demir has the Ph.D. degree in environmental engineering from Istanbul University in 2002. He has the MSc. degree of environmental engineering (1997) and the B.S. degree of biology in Istanbul University (1993). His research interests are air pollution and control, microbial fuel cells and sustainable power generation, water pollution and control. Currently he is working as a professor in Bahcesehir University Department of Environmental Engineering in Istanbul, Turkey.

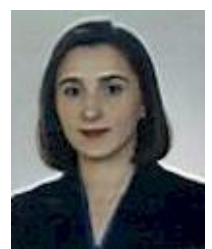

Ayse Kablan graduated from Dokuz Eylul University, Civil Engineering Department in 1996. He has her master degree from Bahecsehir University Urban Systems and Tramsporation Management Department. She is working in Turkey Republic State Railway Department since 1999.

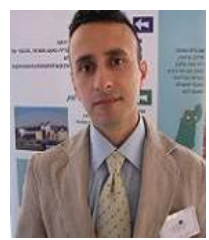

Yasar Avsar graduated from Yildiz Technical University Environmental Engineering Department in 1995. He has his masters degree in the same university with the study subject of "Determination of noise map of Yildiz Technical University and its surroundings". He has completed his $\mathrm{PhD}$ in 2002 in the same university. $\mathrm{He}$ is assigned as an associate professor in Yildiz Technical University. His research areas are wastewater treatment and noise pollution.

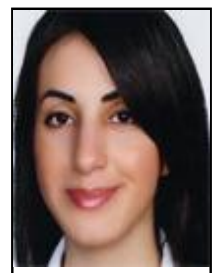

Ummugulsum Alyuz has her MSc. degree of environmental engineering, from Istanbul Technical University in 2012 and an MBA degree from Istanbul University in 2010 and the B.S. degree of environmental engineering from Trakya University in 2008. Currently she is a PhD candidate of Istanbul Technical University Eurasia Earth Systems Institute. Her research interests are air quality modelling, solid waste management.

She is assigned as a research assistant in Bahcesehir University, Istanbu Turkey, the Department of Environmental Engineering in 2012 and worked as an R\&D engineer in Cevka Construction Co. Ltd. from 2008 to 2012 in the solid waste management sector.

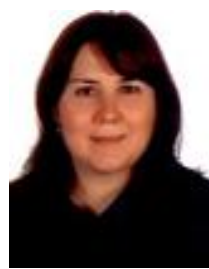

Hatice E. Okten has the Ph.D. degree in environmental engineering, University of Wisconsin-Madison in 2008. She has her M.S. degree in environmental engineering (2002) and the B.S. degree in environmental engineering in Istanbul University (1999). Her research interests are water and wastewater treatment.

She has assigned as an assistant professor in Bahcesehir University, in Istanbul Turkey since 2008 and as a research assistant in Istanbul Technical University between 2000 and 2002.

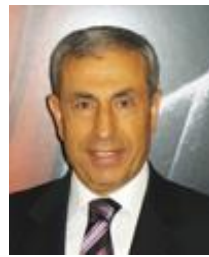

Senay Yalcin has his bachelor, master and $\mathrm{PhD}$ degrees from Ege University of Turkey. He is the professor of Bahcesehir University Energy Systems Engineering. Professor Yalcin's areas of interests include nuclear engineering and environmental sciences. 